\title{
OUVIDORIA: UMA FERRAMENTA ESSENCIAL NA PREVENÇÃO DE CONFLITOS, MITIGAÇÃO DE LITÍGIOS E MELHORIA DE RESULTADOS NAS INSTITUIÇÕES
}

\author{
PLANO DE COOPERAÇÃO ENTRE UNIMED UBERLÂNDIA - MG \\ E PROCON MUNICIPAL
}

Antônio Alves Meireles Junior ${ }^{1}$

\begin{abstract}
Resumo
A aproximação das empresas com os órgãos de proteção ao cliente é de suma importância para a estratégia, a minimização da ocorrência de falhas nos processos, a obtenção de meIhorias no posicionamento de produtos e serviços, além de proporcionar melhor colocação da marca no mercado e, principalmente, estreitar o relacionamento com o cliente que necessita ser acolhido pela empresa contratada. Desse estreitamento, a possibilidade de cativar o cliente com um atendimento personalizado melhora sua jornada dentro da empresa, trazendo benefícios de resolutividade para todos os envolvidos. Nesse sentido, o Plano de Cooperação proposto pela Unimed Uberlândia em parceria com o Procon Municipal visa acolher as demandas dos beneficiários, promovendo assim maior justiça social entre os partícipes e trazendo à luz o diálogo e a compreensão para que haja uma relação de consumo equilibrada para todos.
\end{abstract}

Palavras-chave: Práticas. Planos de Saúde. Resolutividade. Parcerias Público-Privadas.

1 Formado em Administração pela Universidade Federal de Viçosa (UFV) e pós-graduado em Gerenciamento de Projetos pela PUC-MG. É Ouvidor Titular da Unimed Uberlândia MG, com experiência nas áreas de Compliance, Gestão de Riscos e Controles Internos. (ameireles@unimeduberlandia.coop.br) 


\begin{abstract}
The approach of the companies with the organs of protection to the client is of paramount importance for the strategy, the minimization of the occurrence of failures in the processes, the obtaining of improvements in the positioning of products and services, besides providing better placement of the brand in the market and mainly relationship with the client that needs to be accepted by the contracted company. From this narrowing, the possibility of captivating the customer with a personalized service improves the journey of the same within the company bringing benefits of resolution to all involved. In this sense, the Cooperation Plan proposed by Unimed Uberlândia in partnership with Municipal Procon aims to accommodate the demands of the beneficiaries, thus promoting greater social justice among the participants and bringing to light the dialogue and understanding to promote a balanced consumption relationship for all.
\end{abstract}

Keywords: Practices. Health Plans. Solvability. Public-Private Partnerships. 


\section{INTRODUÇÃO}

A grande maioria dos processos judiciais na área da saúde se acumula e se arrasta por longo tempo nos tribunais, resultando em extrapolação de prazos, custo excessivo das operações e gastos judiciais. Esses impasses tendem a comprometer ainda mais a saúde do beneficiário, uma vez que o foco primordial é suprimido, dando lugar às disputas judiciais.

Não é tida como uma relação de consumo saudável aquela que exige um esforço descomunal por parte do cliente e desfavorece o relacionamento entre ele e a empresa prestadora de serviço. O relacionamento desejável necessita ser amparado pelo diálogo e compreensão das partes, única forma de conciliar os anseios dos interessados e trazer resolutividade.

Segundo o Relatório Analítico Propositivo publicado pelo Conselho Nacional de Justiça (CNJ) - 2019, as demandas judiciais relativas à saúde registraram um aumento de $130 \%$ entre os anos de 2008 e 2017. Com relação à Saúde Suplementar, houve um aumento de 30,03\% de casos judicializados. Os percentuais mostram uma relevância significativa na quantidade de judicializações, aumentando o custo dos processos e o tempo de resolutividade. A Figura 1 ilustra o aumento anual do número de processos de saúde nos tribunais de primeira instância.

\section{FIGURA 1 - Número de processos relativos à saúde distribuídos por ano ( $1^{\mathrm{a}}$ instância)}

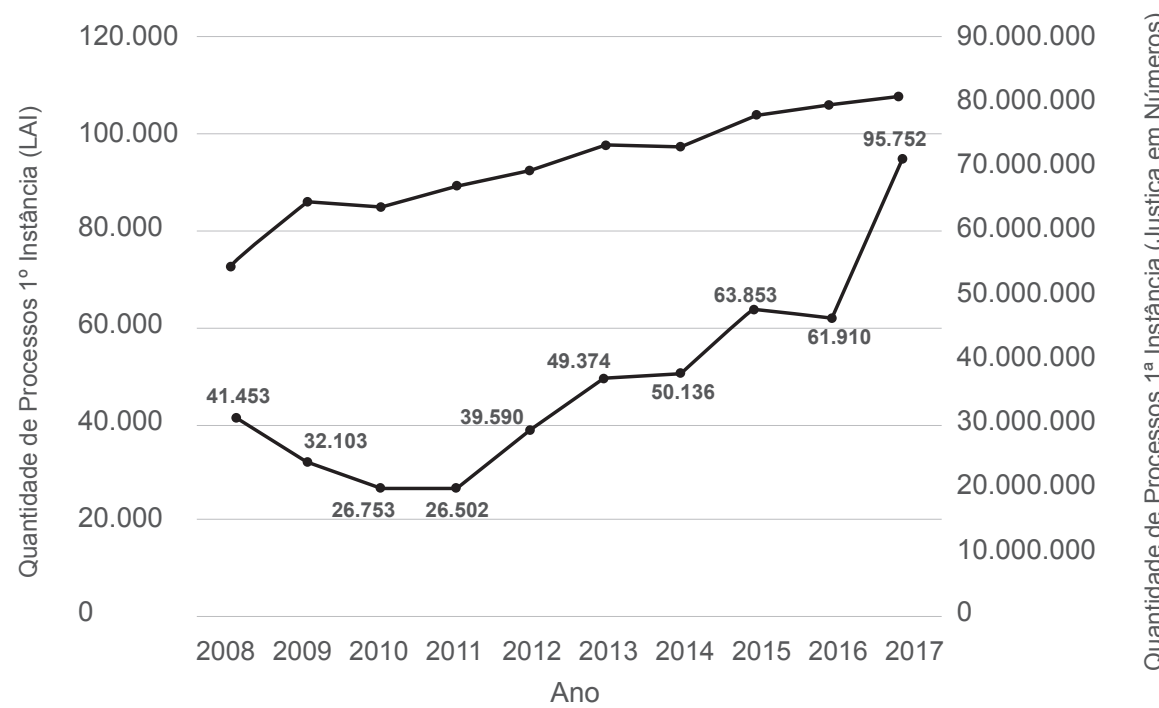

Fonte: CNJ (2019, p. 46)

Diante dessa realidade, é de suma importância que as operadoras de saúde criem meios (mecanismos) que atuem de forma contrária à onda de processos, optando por métodos que busquem 
a resolução consensual em vez de práticas contenciosas. Uma forte atuação das operadoras de saúde nos canais de blindagem como SAC, Mídias Sociais, Reclame Aqui e Procon, considerados de primeira instância, e o empoderamento da Ouvidoria, tido como canal de segunda instância nas instituições, garantem ótimos resultados na redução de riscos ofensores e passivos judiciais como processos e emissão de Notificação de Intermediação Preliminar (NIP) pela Agência Nacional de Saúde Suplementar (ANS).

A Ouvidoria é uma ferramenta que permite ao cidadão acioná-la e ter suas demandas assistidas com menor prazo possível, alto padrão de embasamento legal nas respostas e grande resolutividade. O diálogo proposto pela Ouvidoria transforma as necessidades dos clientes em melhoria de processos, produtos e serviços, aprimorando o atendimento como um todo nos setores da organização (VISMONA, 2011), uma vez que a Ouvidoria está organizacionalmente vinculada e representa a autoridade máxima da empresa.

Para SALES (2006), a Ouvidoria é um serviço que estabelece um canal de comunicação imparcial, equilibrado e democrático, focado em intermediação e na solução de conflitos.

A Ouvidoria é um canal de relacionamento que se propõe a dar voz ao cidadão, acolhendo suas denúncias, dúvidas, elogios, solicitações de informações e outras demandas, reclamações e sugestões, com o objetivo de resolver conflitos que surjam no atendimento ao público, buscando aperfeiçoar os processos de trabalho das empresas, solucionando eventuais deficiências ou falhas na prestação de serviços.

\section{ESFERAS ENVOLVIDAS NO PROCESSO DE RELACIONAMENTO COM O CLIENTE:}

\section{Unimed Uberlândia}

Constituída na Assembleia-Geral realizada em 15 de maio de 1971, a Cooperativa Regional de Trabalho Médico Ltda. - Unimed Uberlândia foi fundada com o comparecimento inicial de 52 médicos cooperados. A Unimed Uberlândia, hoje em seus 48 anos de existência, é uma cooperativa com mais de 87 mil beneficiários (clientes que contratam o plano de saúde), 530 colaboradores, 140 prestadores de serviços credenciados, entre clínicas, laboratórios e hospitais, e 821 médicos cooperados ativos em seu quadro social.

\section{Ouvidoria Unimed Uberlândia}

A Unimed Uberlândia conta com um setor de Ouvidoria institucionalizada a partir da publicação da Resolução Normativa (RN n 323) de 03 de abril de 2013. O setor de Ouvidoria da Unimed Uberlândia está subordinado diretamente ao diretor-presidente, cargo este que é o mais elevado da cooperativa e possui políticas próprias com regimento baseado na regulamentação da Agência Nacional de Saúde Suplementar (ANS) e boas práticas de mercado, como enviar resposta conclusiva ao cliente em até 05 (cinco) dias úteis, sendo este prazo menor do que o estipulado pela Agência 
Nacional de Saúde Suplementar (ANS), forte atuação nos canais de blindagem, melhorando a eficiência dos serviços em atendimento mais próximo ao cliente e mais efetivo.

O setor de Ouvidoria da Unimed Uberlândia conta hoje com o seu Ouvidor titular, um Ouvidor substituto e um Analista de Ouvidoria.

O atendimento da Ouvidoria Unimed Uberlândia é realizado presencialmente, pelas demandas registradas em seu site, Mídias Sociais, Reclame Aqui, Procon ou pelo e-mail: ouvidoria@unimeduberlandia.coop.br.

Um forte trabalho feito pela Ouvidoria da Unimed Uberlândia nos canais de blindagem (canais primários), como Mídias Sociais, Reclame Aqui, SAC e Procon proporciona resoluções mais rápidas e com alto nível de satisfação do cliente. Com o Procon, uma busca de parceria foi primordial para o rápido atendimento e acesso irrestrito do cliente à Ouvidoria, visando assim uma diminuição dos passivos judiciais para a cooperativa.

\section{Procon}

De acordo com a Lei Municipal complementar n 88, de 23 de agosto de 1994, Art. 3º inciso I, o Programa de Proteção e Defesa do Consumidor (Procon) tem como atribuição: coordenar, executar e elaborar a política municipal de proteção e defesa do consumidor, nos limites de sua competência.

O Procon está sob a salvaguarda da Secretaria da Justiça e da Defesa da Cidadania, órgão vinculado ao Sistema Nacional de Defesa do Consumidor conforme estabelecido pelo próprio Código de Defesa do Consumidor (CDC), Lei n 8.078, de 11 de setembro de 1990.

A principal finalidade do Procon é garantir a mediação de casos conflituosos entre os clientes e consumidores insatisfeitos, porém, caso não seja possível realizar um acordo entre o cliente e a empresa demandada, o processo é enviado para o Juizado Especial Cível local.

\section{Desenvolvimento}

Para evitar judicializações no Programa de Proteção e Defesa do Consumidor (Procon) Municipal, a Ouvidoria da Unimed Uberlândia propôs um plano de cooperação para atendimento exclusivo aos consumidores que procurarem o órgão e também ações conjuntas com a finalidade de aumentar a eficiência na resolutividade das demandas, promovendo satisfação do cliente e, principalmente, abertura de diálogo.

O escopo do programa foi apresentado à Superintendência do Procon Municipal, que recebeu a equipe de Ouvidoria da Unimed Uberlândia e o Jurídico da cooperativa com bastante entusiasmo e disposição, visando um atendimento mais ágil, humano e eficaz aos clientes da cooperativa. O Procon Municipal apresentou irrestrito apoio às equipes envolvidas no projeto cedendo espaço físico e colaboradores para treinamento desse novo fluxo de atendimento das demandas oriundas da Unimed Uberlândia. O treinamento da equipe do Procon foi realizado na Unimed Uberlândia pelos colaboradores da Ouvidoria e visou as especificações do atendimento ao usuário do plano de saúde e suas particularidades por ser um meio altamente regulado pela Agência Nacional de Saúde Suplementar (ANS).

A partir dessa parceria, ficou estabelecido que o Procon Municipal não emitiria notificações diretas 
e formais à Unimed Uberlândia, e sim uma Carta de Informações Preliminares (CIP) com os dados do cliente e o motivo da manifestação descrita na demanda. Uma vez recebida, a Unimed Uberlândia teria um prazo máximo de até 05 (cinco) dias úteis para encerramento da demanda. Dentro desse prazo a Ouvidoria enviaria a demanda para a área correspondente e, após o recebimento da resposta, realizaria a conciliação para maior efetividade no tratamento da causa. Caso houvesse aceite por parte do cliente, a Ouvidoria realizaria um acordo entre as partes e enviaria a devolutiva aos envolvidos, mas, se não houvesse acordo, o Procon Municipal notificaria a Unimed Uberlândia formalmente.

A Figura 2 apresenta a modelagem do processo referente ao fluxo de atendimento da CIP desenvolvida pela Ouvidoria da Unimed Uberlândia e enviada como proposta ao Procon Municipal.

\section{FIGURA 2 - Processo plano de cooperação - Unimed Uberlândia e Procon Municipal}

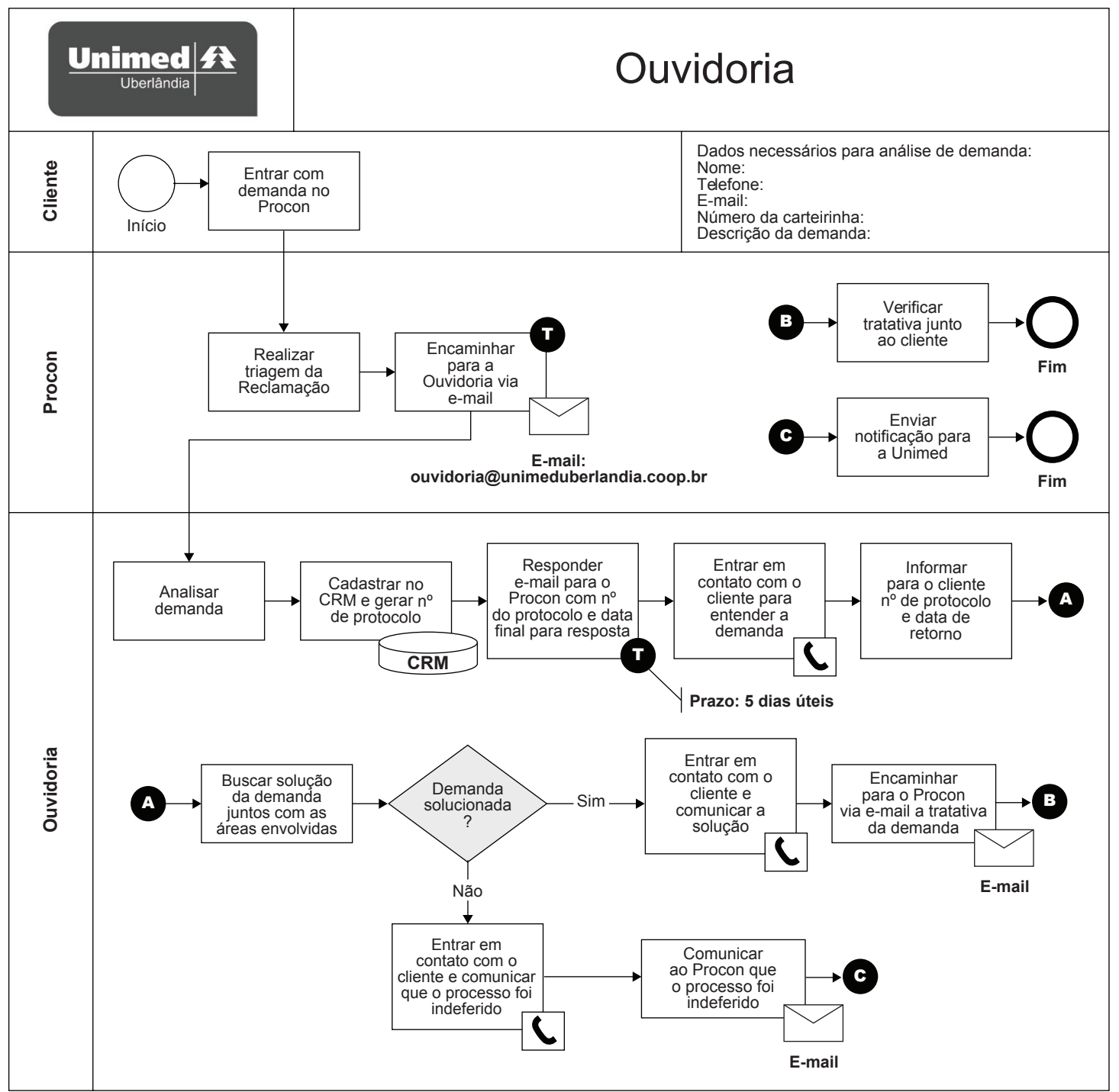




\section{Resultados}

Conforme o Gráfico 1, no ano de 2017 foram registradas 34 notificações diretas do Procon Municipal à Unimed Uberlândia, porém, no ano de 2018, após o plano de cooperação, o Procon Municipal notificou a Unimed Uberlândia por 02 vezes das 32 demandas enviadas à cooperativa via Cartas de Informações Preliminares (CIP).

A notificação direta pelo Procon Municipal à Unimed Uberlândia é um fator agravante para a cooperativa, pois faz com que a demanda seja enviada para tratativas sem antes dar a oportunidade de abertura do diálogo com o cliente. Com o plano de cooperação, o diálogo é favorecido pelo ajuste do processo, trazendo à luz o entendimento e rápida resolutividade.

\section{GRÁFICO 1 - Quantidade de Notificações}

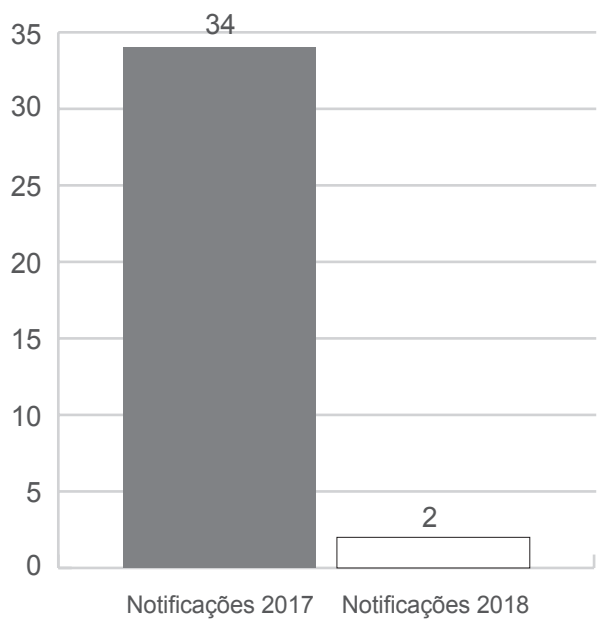

No ano de 2018 não foi constatada nenhuma notificação encaminhada ao Juizado Especial Cível da comarca de Uberlândia MG. Devido às tratativas dadas às demandas e a alta resolutividade, as notificações foram resolvidas sem que o cliente procurasse outras instâncias para recorrer. Todo este trabalho é fruto dos resultados exitosos da parceria com o Procon Municipal e de esforços entre a Ouvidoria da Unimed Uberlândia e seu setor Jurídico.

No Gráfico 2, é possível verificar que, do total das 32 CIPs enviadas no ano de 2018 à Unimed Uberlândia, apenas 8,69\% se converteram em notificações à Unimed Uberlândia, garantindo assim uma eficiência de $91,31 \%$ das CIPs enviadas e resolvidas após a implantação do Plano de Cooperação entre a Unimed Uberlândia e o Procon Municipal. 


\section{GRÁFICO 2 - Índice de resolutividade das demandas enviadas à Ouvidoria Unimed Uberlândia}

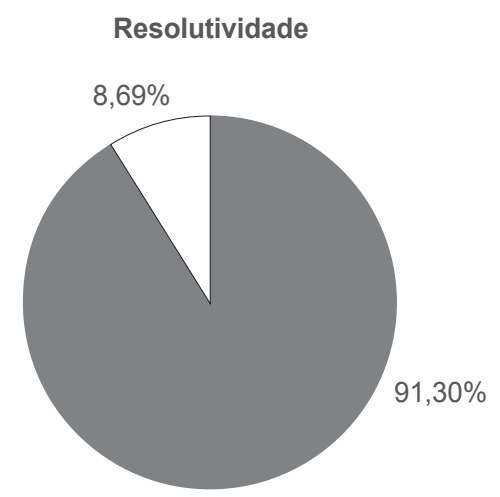

No Gráfico 3, verifica-se que, com o atendimento sendo realizado cumprindo os prazos estabelecidos pela RN 323/13 da Agência Nacional de Saúde (ANS) e atendendo aos requisitos de qualidade da Unimed Uberlândia em atendimento das demandas em 05 (cinco) dias úteis, foi reduzido o tempo de resposta. O tempo médio de resposta caiu de 8,12 dias em 2017 para 1,32 dia no ano de 2018.

\section{GRÁFICO 3 - Tempo médio de resposta da demanda}

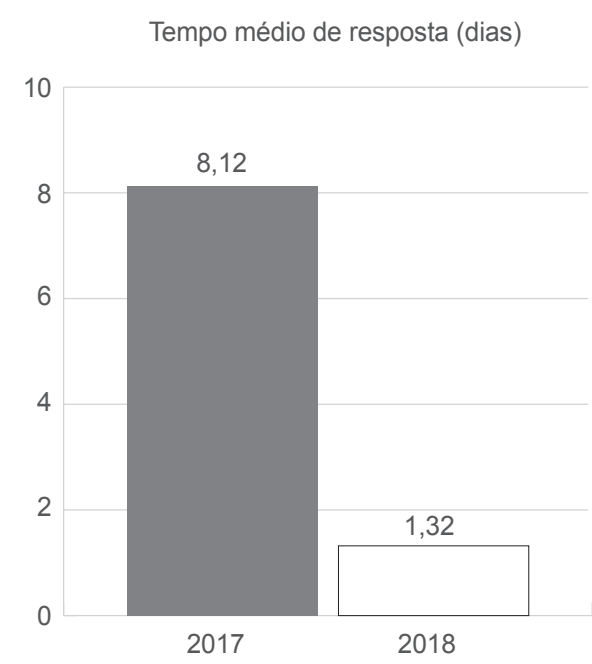

O Gráfico 4 apresenta as porcentagens obtidas a partir da pesquisa de satisfação aplicada a todos os clientes que procuraram o Procon Municipal no ano de 2018 e tiveram suas demandas tratadas pela Ouvidoria Unimed Uberlândia. Nota-se que $87 \%$ estão muito satisfeitos, $6 \%$ satisfeitos, $5 \%$ indiferentes e $2 \%$ pouco satisfeitos com os serviços prestados pela Ouvidoria Unimed Uberlândia. Nota-se que nenhum cliente respondeu que estaria insatisfeito.

Pesquisa aplicada a todos os 32 clientes que abriram demandas no Procon no ano de 2018 através de CIPs enviadas à Ouvidoria Unimed Uberlândia. Vale ressaltar o comprometimento dos clientes para com a pesquisa pela obtenção do retorno de $100 \%$ dos pesquisados. 


\section{GRÁFICO 4 - Pesquisa de satisfação dos clientes com a Ouvidoria Unimed Uberlândia}

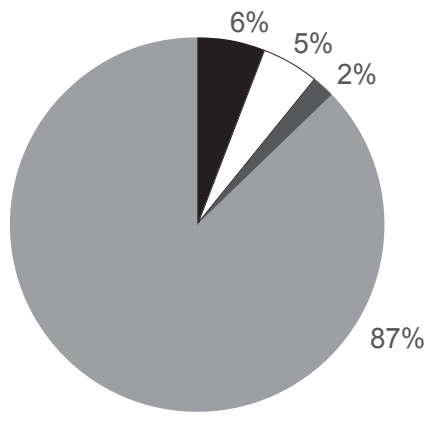

Muito satisfeito

Satisfeito

Indiferente

Pouco satisfeito

O plano de cooperação vai além de alinhamento de processos e atendimento das CIPs. Em 2019, proporcionamos encontros e mutirões de resolução de demandas com o órgão de proteção ao cliente. Na semana em comemoração do dia do consumidor, a Ouvidoria Unimed Uberlândia realizou na sede do Procon Municipal um mutirão de conciliações na busca de massificação de resoluções e atendimentos em curtíssimo prazo aos clientes da cooperativa. Nesse dia foram realizadas 47 conciliações entre a cooperativa e seus clientes, fechando negociações no valor de R\$ $50.760,47$. Este tipo de ação proporcionou satisfação aos clientes Unimed Uberlândia, diminuição de demandas já constantes no Procon Municipal e ganhos financeiros para a Cooperativa.

Os benefícios desses planos de cooperação público-privada podem ser mais bem visualizados conforme Quadro 1, abaixo:

\section{QUADRO 1 - Apresentação das melhorias}

\begin{tabular}{|l|l|}
\hline \multicolumn{1}{|c|}{ ANTES DO PLANO DE COOPERAÇÃO } & \multicolumn{1}{|c|}{ APÓS O PLANO DE COOPERAÇÃO } \\
\hline $\begin{array}{l}\text { Cooperativa era notificada em toda entrada de } \\
\text { demanda no Procon. }\end{array}$ & $\begin{array}{l}\text { Cooperativa recebe uma (CIP) e é realizada } \\
\text { tratativa diretamente com o cliente. }\end{array}$ \\
\hline Prazo protocolar Procon 10 dias & $\begin{array}{l}\text { Demandas resolvidas em até } 5 \text { dias úteis confor- } \\
\text { me preconiza RN 323/13 (ANS) e processos de } \\
\text { qualidade da Unimed Uberlândia. }\end{array}$ \\
\hline Baixa resolutividade & Alta resolutividade \\
\hline Canais difusos & Canal único e exclusivo \\
\hline Processo & Diálogo \\
\hline Alto esforço do cliente & Menor esforço do cliente \\
\hline
\end{tabular}




\section{CONSIDERAÇÕES}

A desjudicialização através do diálogo é a melhor forma de encontrarmos efetividade na diminuição de litígios e passivos judiciais que prejudicam as instituições e a comunidade como um todo. Cremos sempre que a última forma de se resolver pendências de demandas seja nos tribunais, pois podem gerar gastos e resultados não esperados a todos/alguns interessados. A Ouvidoria é parceira dos clientes quando está em compliance com o Código de Defesa do Consumidor, pois é capaz de promover entendimentos e buscar pacificação nas relações de consumo. A Ouvidoria é uma aliada na busca do diálogo e soluções e, sob a ótica das empresas, uma ferramenta essencial na tomada de decisões, mitigação de litígios, aumento de receita e aproximação de seus clientes visando satisfação.

\section{REFERÊNCIAS}

BRASIL. Lei $n^{\circ}$ 8.078, de 11 de setembro de 1990. Código de Defesa do Consumidor. Dispõe sobre a proteção do consumidor e dá outras providências. Disponível em: http://www.planalto.gov.br/ccivil_03/leis//8078.htm.

Ministério da Saúde. Agência Nacional de Saúde Suplementar. Resolução Normativa n 323, de 03 de abril de 2013. Dispõe sobre a instituição de unidade organizacional específica de Ouvidoria pelas operadoras de planos privados de assistência saúde.

CONSELHO NACIONAL DE JUSTIÇA. Judicialização da Saúde no Brasil. Perfil das demandas, causas e Propostas de Solução. Brasília: CNJ, 2019. Disponível em: http://www.cnj.jus.br/files/conteudo/arquivo/2019/03/66361404dd5ceaf8c5f7049223bdc709.pdf. Acesso em: jun. 2019.

SALES, L. M. M. Ouvidoria e mediação: instrumentos de acesso à cidadania. Pensar, Fortaleza, v. 11, p. 154-167, 2006.

UBERLÂNDIA. Lei complementar $n^{\circ} 88$, de 23 de agosto de 1994. Disponível em: https://leismunicipais.com.br/a1/ $\mathrm{mg} / \mathrm{u} / \mathrm{uberlandia/lei-complementar/1994/8/88/lei} \mathrm{complementar-n-88-1994-organiza-o-sistema-municipal-de-pro-}$ tecao-e-defesa-do consumidor-e-da-outras-providencias.

VISMONA, Edson. A evolução das Ouvidorias no Brasil. In: PEREZ, José; BARREIRO, Adriana; PASSONE, Eric (Org.). Construindo a Ouvidoria no Brasil: avanços e perspectivas. Campinas: Unicamp, 2011. 